\title{
Uncertainties in estimating mercury emissions from coal-fired power plants in China
}

\author{
Y. Wu ${ }^{1}$, D. G. Streets ${ }^{2}$, S. X. Wang ${ }^{1}$, and J. M. Hao ${ }^{1}$ \\ ${ }^{1}$ Department of Environmental Science and Engineering, and State Key Joint Laboratory of Environment Simulation and \\ Pollution Control, Tsinghua University, Beijing 100084, China \\ ${ }^{2}$ Decision and Information Sciences Division, Argonne National Laboratory, Argonne, Illinois 60439, USA
}

Received: 27 September 2009 - Published in Atmos. Chem. Phys. Discuss.: 5 November 2009

Revised: 17 March 2010 - Accepted: 20 March 2010 - Published: 29 March 2010

\begin{abstract}
A detailed multiple-year inventory of mercury emissions from anthropogenic activities in China has been developed. Coal combustion and nonferrous metals production continue to be the two leading mercury sources in China, together contributing $\sim 80 \%$ of total mercury emissions. However, many uncertainties still remain in our knowledge of primary anthropogenic releases of mercury to the atmosphere in China. In situations involving large uncertainties, our previous mercury emission inventory that used a deterministic approach could produce results that might not be a true reflection of reality; and in such cases stochastic simulations incorporating uncertainties need to be performed. Within our inventory, a new comprehensive submodule for estimation of mercury emissions from coal-fired power plants in China is constructed as an uncertainty case study. The new sub-module integrates up-to-date information regarding mercury content in coal by province, coal washing and cleaning, coal consumption by province, mercury removal efficiencies by control technology or technology combinations, etc. Based on these detailed data, probability-based distribution functions are built into the submodule to address the uncertainties of these key parameters. The sub-module incorporates Monte Carlo simulations to take into account the probability distributions of key input parameters and produce the mercury emission results in the form of a statistical distribution. For example, the best estimate for total mercury emissions from coal-fired power plants in China in 2003 is $90.5 \mathrm{Mg}$, with the uncertainty range from $57.1 \mathrm{Mg}(\mathrm{P} 10)$ to $154.6 \mathrm{Mg}(\mathrm{P} 90)$; and the best estimate for elemental mercury emissions is $43.0 \mathrm{Mg}$, with the uncertainty range from $25.6 \mathrm{Mg}$ (P10) to $75.7 \mathrm{Mg}$ (P90). The
\end{abstract}

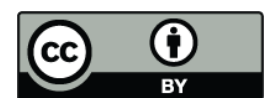

Correspondence to: $\mathrm{Y} . \mathrm{Wu}$

(ywu@tsinghua.edu.cn) results further indicate that the majority of the uncertainty in mercury emission estimation comes from two factors: mercury content of coal and mercury removal efficiency.

\section{Introduction}

Concern about mercury $(\mathrm{Hg})$ in the environment has grown as its dangerous effects are well established. The confirmation of the ability of elemental mercury $\left(\mathrm{Hg}^{0}\right)$ to undergo long-range transport at hemispheric scale (Banic et al., 2003; Dastoor and Larocque, 2004; Seigneur et al., 2001; Travnikov and Ryaboshapko, 2002) intensifies the anxiety in some countries/regions that the quantities of imported atmospheric $\mathrm{Hg}$ may be substantial and may interfere with the ability of domestic sources to comply with future emission limitations (Jaffe et al., 2005; Seigneur et al., 2004; Selin et al., 2007; Steding and Flegal, 2002; Weiss-Penzias et al., 2007). For example, Seigneur et al. (2004) estimated that anthropogenic emissions of mercury in Asia contributed 21\% to total mercury deposition in the contiguous United States in 1998.

During the past two decades considerable progress has been made in better estimating anthropogenic $\mathrm{Hg}$ sources at global-scale as well as at national-scale. Pacyna and his co-workers continue to update global $\mathrm{Hg}$ emission inventories, and they have generated estimates of $2140 \mathrm{Mg}$ for 1990 , $1910 \mathrm{Mg}$ for 1995 , and $2190 \mathrm{Mg}$ for 2000 (Pacyna and Pacyna, 1996, 2002; Pacyna et al., 2006). According to the most recent global inventory, about $65 \%$ of emissions came from stationary fuel combustion in 2000; geographically, about $54 \%$ of the emissions came from Asia, and China was the largest Hg emitting country (Pacyna et al., 2006).

Published by Copernicus Publications on behalf of the European Geosciences Union. 
Mercury contamination is a serious problem in China. Feng (2005) has summarized a number of specific instances associated with industrial releases of $\mathrm{Hg}$ in past years. High concentrations of $\mathrm{Hg}$ in the air of China's cities have also been reported in several studies (Fang et al., 2001; Feng et al., 2003, 2004a, b; Liu et al., 2002). Furthermore, Hg concentrations measured in the air of remote areas in China are also significantly higher than other remote areas in the Northern Hemisphere (Fu et al., 2009, 2010; Lindberg et al., 2007; Wan et al., 2009), which suggests contamination of remote areas of China by anthropogenic $\mathrm{Hg}$ emissions. Recently, a better understanding of China's $\mathrm{Hg}$ emissions has been made. Since 2003, Tsinghua University and Argonne National Laboratory have been developing a comprehensive multiple-year inventory of $\mathrm{Hg}$ emissions from anthropogenic sources in China, following the precedent of the Asian TRACE-P emission inventory (Streets et al., 2003a, 2003b). We have developed a detailed assessment of emissions from coal combustion with a new technology-based treatment for each province, supplemented with estimates of emissions from all other significant man-made sources (no natural sources or re-emission). $\mathrm{Hg}$ emissions are speciated using technology-specific factors and gridded for use in atmospheric models. A detailed estimation of China's mercury emissions by province for the year 1999 is presented in Streets et al. (2005), and the trends in anthropogenic $\mathrm{Hg}$ emissions in China from 1995 to 2003 are presented in Wu et al. (2006). $\mathrm{Hg}$ emissions were stable at around $540( \pm 20) \mathrm{Mg}$ during the period 1995-2000, but increased quickly to nearly $700 \mathrm{Mg}$ in 2003. Coal combustion and nonferrous metals production continue to be the two leading mercury sources in China, together contributing $\sim 80 \%$ of total mercury emissions over the past decade (Wu et al., 2006).

However, many uncertainties still remain in our knowledge of primary anthropogenic releases of mercury to the atmosphere in China. Specifically, we are lacking actual measurements of $\mathrm{Hg}$ emission rates and $\mathrm{Hg}$ species profiles from Chinese combustors and the capture of $\mathrm{Hg}$ in Chinese emission control devices. There are even large discrepancies in estimates of the typical $\mathrm{Hg}$ content of coal in many provinces. Based on a preliminary uncertainty analysis with coefficients of variation of various contributing factors and combining total uncertainties with quadrature average, approximately $\pm 40 \%$ for power plants, $\pm 60 \%$ for industrial coal use, and even larger uncertainty ranges for other sources were estimated for $\mathrm{Hg}$ emissions in China in 1999 (Streets et al., 2003a, 2005). Further, the gap between $\mathrm{Hg}$ emission inventories and atmospheric observations (Friedli et al., 2004; Jaffe et al., 2005; Pan et al., 2006; Weiss-Penzias et al., 2007; Wu et al., 2006), has been driving an urgent need to better understand the uncertainties embedded in the $\mathrm{Hg}$ emission estimate.

In this paper, we present a new comprehensive sub-module within our previous $\mathrm{Hg}$ emission inventory (Streets et al., 2005; Wu et al., 2006) for estimation of $\mathrm{Hg}$ emissions from coal-fired power plants in China as an uncertainty case study. With this effort, stochastic simulation capability is incorporated into the model to address uncertainties. Distribution functions are built for the key parameters, such as the $\mathrm{Hg}$ content of coal and the $\mathrm{Hg}$ removal efficiencies of major control technologies. We take into account probability distributions of those key input parameters, and produce the $\mathrm{Hg}$ emission results in the form of statistical distributions. For this paper, the uncertainty results in $\mathrm{Hg}$ emissions for the year 2003 are presented and discussed.

\section{Methodology, data sources, and key assumptions}

A new sub-module has been developed to conduct uncertainty analysis of $\mathrm{Hg}$ emissions from coal-fired power plants in China. Mercury emissions are calculated using coal consumption data and detailed $\mathrm{Hg}$ emission factors. The basic concept of the $\mathrm{Hg}$ emission calculation is described by the equation:

$$
E=\sum_{i} \sum_{j}\left[e f_{i, j} \cdot A_{i, j} \cdot F_{\mathrm{REL} \mathrm{j}} \cdot\left(1-F_{\mathrm{REM} \mathrm{j}}\right)\right]
$$

where $E$ is the $\mathrm{Hg}$ emission; $e f_{i, j}$ is the $\mathrm{Hg}$ content of coal as burned; $A_{i, j}$ is the amount of coal consumption; $F_{\mathrm{REL} j}$ is the fraction of $\mathrm{Hg}$ released to the atmosphere; $F_{\mathrm{REM} j}$ is the fraction of $\mathrm{Hg}$ removed by emission control devices; $j$ is the combustor type with/without emission control devices; and $i$ is the province.

The new module has up-to-date information regarding mercury content in coal by province, coal washing and cleaning, coal consumption by province, mercury removal efficiencies by control technology or technology combinations, share of each control technology to coal power capacity in China, etc. As these parameters used in our new sub-module involve uncertainties, we establish probability distribution functions for them on the basis of the available data. Many of these were already collected and published in our previous papers (Streets et al., 2005, 2008; Wu et al., 2006), supplemented with other newly available test data from various researchers. To accomplish this, the data from each source type are read into Crystal Ball ${ }^{\mathrm{TM}}$, a statistical software package, which, based on the number of data points and scatter of the data, attempts to fit a distribution about the data for that source type. In Crystal Ball ${ }^{\mathrm{TM}}$, a mathematical fit is performed to determine the set of parameters for each set of standard distribution functions that best describes the characteristics of the data. In this study, the goodness-of-fit is determined using the Chi-square test and Anderson-Darling test. The Chi-square test is the oldest and most common goodness-of-fit test. This test gauges the general accuracy by breaking down the distribution into areas of equal probability and compares the data points with each area to the number of expected data points. Generally, a $p$-value greater than 0.5 indicates a close fit. However, for those parameters with 
Table 1. Key characteristics for distribution functions of mercury content of raw coal by major provinces in China (mercury content in ppm).

\begin{tabular}{lllllll}
\hline Parameters & Number of samples & Distribution function type & P10 $^{\mathrm{a}}$ & P50 $^{\mathrm{a}}$ & P90 $^{\mathrm{a}}$ & Mean \\
\hline Anhui & 12 & Lognormal & 0.090 & 0.210 & 0.490 & 0.261 \\
Guizhou & 46 & Lognormal & 0.121 & 0.357 & 1.051 & 0.509 \\
Hebei & 13 & Lognormal & 0.036 & 0.111 & 0.343 & 0.164 \\
Heilongjiang & 12 & Lognormal & 0.040 & 0.077 & 0.150 & 0.088 \\
Henan & 18 & Lognormal & 0.058 & 0.171 & 0.505 & 0.245 \\
Liaoning & 8 & Lognormal & 0.043 & 0.134 & 0.418 & 0.189 \\
Nei Mongol & 7 & Lognormal & 0.098 & 0.192 & 0.379 & 0.221 \\
Shaanxi & 9 & Lognormal & 0.008 & 0.051 & 0.317 & 0.141 \\
Shandong & 18 & Lognormal & 0.060 & 0.141 & 0.330 & 0.176 \\
Shanxi & 69 & Lognormal & 0.024 & 0.091 & 0.347 & 0.157 \\
Sichuan & 17 & Lognormal & 0.050 & 0.114 & 0.260 & 0.140 \\
China & $218^{\mathrm{b}}$ & Lognormal & 0.029 & 0.105 & 0.376 & 0.172 \\
\hline
\end{tabular}

${ }^{\text {a }} \mathrm{P} 10$ values mean that there is a probability of $10 \%$ that the actual result would be equal to or below the P10 values; P50 mean that there is a probability of $50 \%$ that the actual result would be equal to or below the P50 values; and P90 mean that there is a probability of $90 \%$ that the actual result would be equal to or below the P90 values.

b All the 218 samples are from the USGS database (USGS, 2004).

a long tail of the distribution, we apply the more appropriate Anderson-Darling method instead. This goodness-of-fit test method closely resembles the Kolmogorov-Smirnov test, except that it weights the differences between the two distributions at their tails greater than at their mid-ranges. We use this test when we need a better fit at the extreme tails of the distributions, such as the lognormal distribution for Hg content in raw coal (see Fig. 1 as an example). Ideally, statistics based on real-world measurements would be employed for this purpose. However, limited data availability sometimes prevents us from taking this approach. In these cases, judgments are made to develop subjective distribution functions (Subramanyan et al., 2008). All distributions are visually examined for reasonableness.

By using Crystal Ball ${ }^{\mathrm{TM}}$, the sub-module incorporates a Monte Carlo stochastic simulation approach to take into account the probability distributions of key input parameters and produce the mercury emission results in the form of a statistical distribution. The Monte Carlo sampling technique is one of the most widely used techniques for sampling from a probability distribution, which is based on a pseudo-random generator used to approximate a uniform distribution (i.e., having equal probability in the range from 0 to 1 ). The specific values for each input variable are selected by inverse transformation over the cumulative probability distribution. The Monte Carlo sampling technique also has the important property that the successive points in the sample are independent. To obtain reliable distribution results, the stochastic simulations were run up to 4000 samples for each forecast variable, e.g., the total $\mathrm{Hg}$ emission for Guizhou Province. At the same time, a precision control confidence level (95.0\% in this study) was set up to ensure the quality of output results.
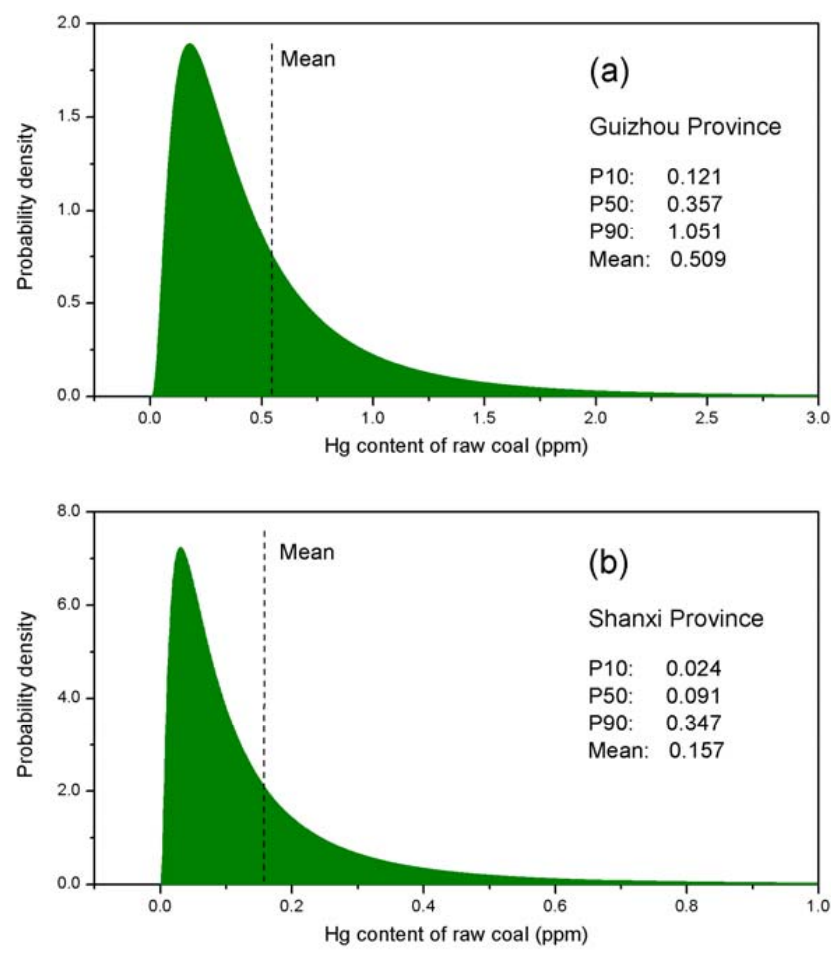

Fig. 1. Distribution function curves for $\mathrm{Hg}$ Content of Raw Coal, (a) Guizhou Province; and (b) Shanxi Province.

\subsection{Mercury content of coal}

A variety of measurement data, including the new USGS database and different Chinese databases (Huang and Yang, 2002; Feng et al., 2002; Streets et al., 2005; USGS, 2004; 
Wang et al, 2000; Wu et al., 2006; Zhang et al., 1999), were gathered to build the distribution functions for the $\mathrm{Hg}$ Content of Raw Coal by province. As bituminous coal is the dominant coal type for coal-fired power plants in China, we exclude other coal samples (e.g., anthracite and lignite) in our databases. Fig. 1 shows example distribution curves for the $\mathrm{Hg}$ content of raw bituminous coal in two provinces (Guizhou and Shanxi). Using the Chi-squared test and the Anderson-Darling test, a lognormal distribution function is found to best fit the data for the two provinces. The key characteristics (such as P10, P50 and P90 values) of the distribution functions for mercury content of raw coal by major provinces in China are summarized in Table 1. For other provinces that lack sufficient coal samples, we use two ways to solve the problem. First, for those provinces we believe are in similar coal geological regions, we apply the calculated distribution curve from a related province to the province that lacks data. For example, we apply the distribution curve of Anhui for Zhejiang. For provinces that do not clearly have comparable coal geology, we simply apply the nationalaverage distribution curve.

It should be noted that the P50 values are significantly lower than the mean values used in our previous papers (Streets et al., 2005; Wu et al., 2006). For example, the P50 value of the $\mathrm{Hg}$ content of coal in Guizhou Province is $0.36 \mathrm{ppm}$, whereas its mean value is $0.51 \mathrm{ppm}$, which is much higher. This is because of the nature of the lognormal distribution curve, which has a long tail (see Fig. 1, e.g., the $\mathrm{P} 90$ value of $\mathrm{Hg}$ content for Guizhou's coal is as high as $1.05 \mathrm{ppm})$. Although there are quite a few coal samples that have high $\mathrm{Hg}$ content, we believe the dominant Chinese coal mines have lower $\mathrm{Hg}$ content (see Table 1).

\subsection{Coal consumption by province}

The data on coal consumption for power plants are primarily from two data sources: China Energy Statistics Yearbook (2005) and China Power Industry Yearbook (2004). The two datasets match reasonably well, within $\pm 5 \%$ for the majority of provinces. Because there is uncertainty in these estimates, but not as a result of measurement error that can be statistically sampled, a triangular distribution function is built for each province. It should be noted that the selection of a triangular distribution is a subjective judgment. Due to the limitation of data (here we only have two data samples), neither the Chi-square test nor the Anderson-Darling test could be used to build the distribution curve. Usually, the triangular or normal distribution function is applied for limited data samples (Brinkman et al., 2005). For this parameter, we set the two statistical data points of coal consumption by each province as the minimum and the maximum values, and the average of the two as the most likely value to build the triangular distribution function. Two examples for raw coal consumption in Guizhou Province and Shanxi Province are shown in Table 2.

\subsection{Mercury removal efficiency by control technology}

In the model, the Hg removal efficiencies of three postcombustion control technologies or technology combinations are built with distribution functions. They are PM scrubbers, electrostatic precipitators (ESPs), and ESPs plus fluegas desulfurization (FGD). In 2003, the share of ESP installation in the total coal-fired power capacity was $\sim 95 \%$ nationwide, and the majority of the remaining $5 \%$ was installed with PM scrubbers. Since the mid 1990's, FGD began to be installed in power plants to reduce $\mathrm{SO}_{2}$ emissions in China. By the end of 2003, the FGD capacity had reached $6.9 \mathrm{GW}$, $\sim 2.5 \%$ of total coal-fired generating capacity. It should be noted that the shares of control technologies vary significantly from one province to another. For example, all the coal power in Beijing was installed with ESP in 2003, among which $\sim 24 \%$ was supplemented with FGD. In this study, we apply the provincial-level technology data for our emission inventory calculations.

At the present time there are 25 test values for ESPs, of which 18 are from the US EPA database (US EPA, 1997, 2002; Srivastava et al., 2006) and seven are Chinese test data from various sources (Chen et al, 2007; Wang et al., 2000, 2010a, b; Zhang et al., 2008; Zhou et al., 2008; Zhu et al., 2002). These Chinese tests applied standardized test protocols, such as the Ontario Hydro Method, which provides a good basis for comparison with US test data. It should be noted that all the test results are for bituminous coal. The removal efficiency of the seven Chinese tests ranges from $20.4 \%$ to $41.0 \%$, with an average of $30.4 \%$, which matches well with the average of the US test data, $29.4 \%$. A Weibull distribution is found to fit the best for the dataset with both the Chi-squared test and the Anderson-Darling test, as shown in Fig. 2. The best estimate (P50 value) is $29.4 \%$ for $\mathrm{Hg}$ removal efficiency by ESP, ranging from $8.8 \%$ (P10) to $50.0 \%$ (P90). It should be noted that the distribution curve is truncated at the left side (see Fig. 2), because the Hg removal efficiency cannot be less than 0 .

The data for PM scrubbers and for ESPs plus FGD are scarce, so we have used the limited data from US tests to build the function curve. It should be noted that even the US data samples for scrubbers and ESPs plus FGD are not enough to build such a distribution curve, so we assume that the Weibull distribution curve (which best fits for ESPs) fits for these two technologies. For FGD plus ESP, we have two data samples available. We set the lower number as the P10 value, the higher as the $\mathrm{P} 90$ value, and the average of the two as the P50 value. For PM scrubbers, we follow the same procedure. These curves need to be updated as soon as more test data become available. For pre-combustion control technology, we apply a Weibull distribution function for coal washing, which is based on limited test data (Streets et al., 2005; Wu et al., 2006). The best estimate values (P50) are $6.5 \%, 69.0 \%$, and $25.0 \%$ for $\mathrm{Hg}$ removal efficiency by scrubber, ESP+FGD, and coal washing, respectively. The 
Table 2. Key characteristics for distribution functions of coal consumption, Hg removal efficiency, and other key parameters.

\begin{tabular}{|c|c|c|c|c|c|c|}
\hline Parameters & $\begin{array}{l}\text { Number of } \\
\text { samples }\end{array}$ & $\begin{array}{l}\text { Distribution } \\
\text { function type }\end{array}$ & $\mathrm{P} 10^{\mathrm{a}}$ & $\mathrm{P} 50^{\mathrm{a}}$ & $\mathrm{P} 90^{\mathrm{a}}$ & Mean \\
\hline \multicolumn{7}{|l|}{ Coal consumption, $10^{3} \mathrm{Mg}$} \\
\hline 1) Guizhou & 2 & Triangular ${ }^{\mathrm{b}}$ & 21647 & 21669 & 21691 & 21669 \\
\hline 2) Shanxi & 2 & Triangular ${ }^{b}$ & 45285 & 46575 & 47866 & 46575 \\
\hline \multicolumn{7}{|l|}{ Hg removal efficiency by control technology, $\%$} \\
\hline 1) PM Scrubber & 2 & Weibull & 4.3 & 6.5 & 8.7 & 6.5 \\
\hline 2) ESP & 25 & Weibull & 8.8 & 29.4 & 50.0 & 30.4 \\
\hline 3) FGD+ESP & 2 & Weibull & 63.0 & 69.0 & 75.0 & 69.0 \\
\hline 4) coal washing & 5 & Weibull & 5.0 & 25.0 & 64.0 & 30.0 \\
\hline $\begin{array}{l}\text { The ratio of clean coal output to raw coal input, } \% \\
\text { Hg speciation split, } \%\end{array}$ & 20 & Logistic & 67 & 80 & 92 & 79 \\
\hline 1) no control, $\mathrm{Hg}^{2+}$ & 6 & Triangular ${ }^{b}$ & 26 & 36 & 46 & 36 \\
\hline $\mathrm{Hg} p$ & 6 & Triangular ${ }^{b}$ & 5 & 25 & 45 & 25 \\
\hline 2) $\mathrm{ESP}, \mathrm{Hg}^{2+}$ & 5 & Triangular ${ }^{b}$ & 32 & 51 & 70 & 51 \\
\hline $\mathrm{Hg}^{p}$ & 5 & Triangular ${ }^{\mathrm{b}}$ & 1 & 2 & 3 & 2 \\
\hline 3) FGD+ESP, $\mathrm{Hg}^{2+}$ & 4 & Triangular ${ }^{b}$ & 0 & 12 & 24 & 12 \\
\hline $\mathrm{Hg}^{p}$ & 4 & Triangular ${ }^{b}$ & 0 & 0.5 & 1 & 0.5 \\
\hline
\end{tabular}

${ }^{\text {a }} \mathrm{P} 10$ values mean that there is a probability of $10 \%$ that the actual result would be equal to or below the P10 values; P50 mean that there is a probability of $50 \%$ that the actual result would be equal to or below the P50 values; and P90 mean that there is a probability of $90 \%$ that the actual result would be equal to or below the P90 values.

$\mathrm{b}$ These values are for the minimum, the most likely, and the maximum values for the triangular distribution function instead of P10, P50, and P90 values.

key characteristics for each of the above distribution curves are summarized in Table 2.

\subsection{The ratio of clean coal output to raw coal input}

In 2003 , clean coal contributed $2.2 \%$ of total coal consumption for the power sector in China. The ratios of cleaned coal output to raw coal input are derived from the Energy Statistics Yearbook (2005). A logistic distribution function is found to fit the best for the dataset. The P10, the best estimate (P50), and P90 values are $0.67,0.80$, and 0.92 , respectively, for the ratio. Table 2 presents the key characteristics for this parameter.

\subsection{Mercury speciation split}

The limited Chinese test data on coal-fired power plant boilers show significant differences in $\mathrm{Hg}$ speciation. The key finding is that the share of $\mathrm{Hg}^{0}$ to total $\mathrm{Hg}$ in Chinese boilers is much higher than that found in US boilers. For example, the share of $\mathrm{Hg}^{0}$ is $26 \%( \pm 15 \%)$ on average for the outlet of ESPs tested in the 18 US boilers (US EPA, 1997, 2002; Srivastava et al., 2006), while this same ratio increases to $48 \%$ $( \pm 11 \%)$ on average for six Chinese boilers (Chen et al, 2007; Wang et al., 2010a; Zhu et al., 2002). The chlorine content of coal could be a major factor causing this difference. Zhang et al. (2008) indicate that the chlorine content of Chinese coals is generally lower than US coals. Chlorine can enhance the

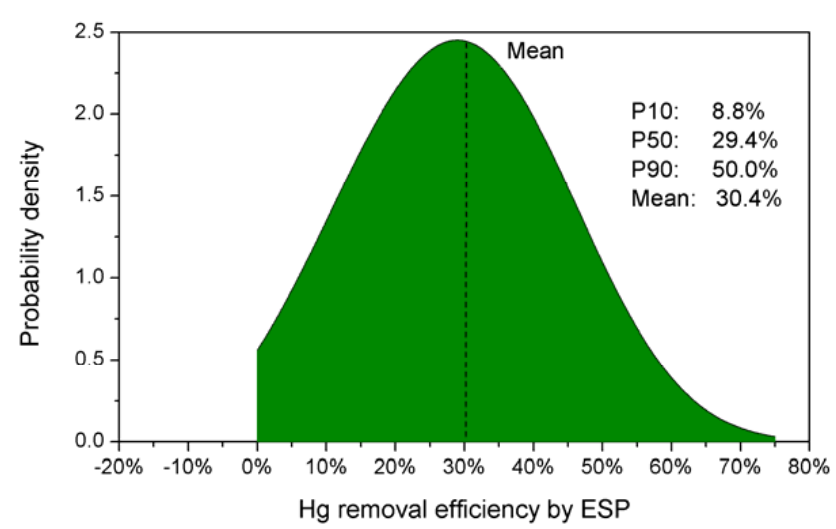

Fig. 2. Distribution function curve for $\mathrm{Hg}$ removal efficiency by ESP.

transformation from $\mathrm{Hg}^{0}$ to divalent $\mathrm{Hg}\left(\mathrm{Hg}^{2+}\right)$ (Chen et al., 2007; Srivastava et al., 2006). The other finding is that the share of particulate $\mathrm{Hg}\left(\mathrm{Hg}^{p}\right)$ to total $\mathrm{Hg}$ for those measurements taken from the inlets of ESPs is significantly lower from Chinese tests compared with US tests (19\% on average for Chinese data vs. $45 \%$ on average for US data). We do not yet know the reason for this difference, but we suspect that the high share of $\mathrm{Hg}^{0}$ could be a factor. More test data are necessary to support the two findings. The built-in distribution curve is based on the limited Chinese test data only 
Table 3. The contributions of various parameters to the uncertainty in $\mathrm{Hg}$ emissions in China and Guizhou Province in 2003.

\begin{tabular}{lllll}
\hline & & China & \multicolumn{2}{c}{ Guizhou Province } \\
\hline & P50, Mg & Uncertainty range & P50, Mg & Uncertainty range \\
Baseline $^{\mathrm{a}}$ & 90.5 & $-36.8 \% /+70.9 \%$ & 5.4 & $-68.0 \% /+199.8 \%$ \\
Scenario $^{\mathrm{b}}$ & 90.0 & $-29.5 \% /+60.4 \%$ & 5.4 & $-65.3 \% /+194.5 \%$ \\
Scenario 2 $^{\mathrm{c}}$ & 102.2 & $-27.7 \% /+25.3 \%$ & 7.9 & $-27.9 \% /+25.5 \%$ \\
Scenario 3 $^{\mathrm{d}}$ & 101.5 & $-0.3 \% /+0.2 \%$ & 7.9 & $-0.1 \% /+0.1 \%$ \\
Scenario 4 $^{\mathrm{e}}$ & 101.6 & $-1.0 \% /+0.7 \%$ & 7.9 & $-0.8 \% /+0.5 \%$ \\
Scenario 5 $^{\mathrm{f}}$ & 101.4 & $-0.4 \% /+0.4 \%$ & 7.9 & $-0.1 \% /+0.0 \%$ \\
\hline
\end{tabular}

a Baseline is a complete stochastic simulation with all parameters in this study built with distribution functions.

b Scenario 1 only sets the parameter, $\mathrm{Hg}$ content in coal, with distribution functions. The distribution functions for other parameters are removed. The results show the contribution of $\mathrm{Hg}$ content in coal to uncertainties of total $\mathrm{Hg}$ emissions.

${ }^{c}$ Scenario 2 only sets the parameter, $\mathrm{Hg}$ removal efficiency by ESP, with distribution functions.

d Scenario 3 only sets the parameter, $\mathrm{Hg}$ removal efficiency by other controls, such as $P M$ scrubber, with distribution functions.

e Scenario 4 only sets the parameter, coal washing and cleaning, with distribution functions.

${ }^{\mathrm{f}}$ Scenario 5 only sets the parameter, coal consumption, with distribution functions.

(Chen et al, 2007; Wang et al., 2010a; Zhu et al., 2002), and we assume that the triangular distribution function best fits the dataset. This may be subject to change when more test data become available. Table 2 summarizes the key characteristics of the distribution curves for $\mathrm{Hg}^{2+}$ and $\mathrm{Hg}^{p}$. For example, the most likely estimates for the share of $\mathrm{Hg}^{2+}$ and the share of $\mathrm{Hg}^{P}$ to total $\mathrm{Hg}$ are $51 \%$ and $2 \%$, respectively, for the outlet of ESPs.

\section{Results and discussion}

With the Crystal Ball ${ }^{\mathrm{TM}}$ software, we apply the Monte Carlo method to perform the stochastic simulations. To get reliable outputs, we set the sampling number as 4000. All the results of total $\mathrm{Hg}, \mathrm{Hg}^{0}, \mathrm{Hg}^{2+}$, and $\mathrm{Hg}^{p}$ by each province are now represented by distribution curves instead of single points. Figure $3 \mathrm{a}-\mathrm{d}$ presents the output distribution curves for emissions of total $\mathrm{Hg}, \mathrm{Hg}^{0}, \mathrm{Hg}^{2+}$, and $\mathrm{Hg}^{p}$, respectively, from coal-fired power plants in China in 2003. We also illustrate all the results for a specific province, Guizhou, as an example, which are shown in Fig. 4a-d.

The curves show a wide range in uncertainties. For example, the total $\mathrm{Hg}$ emissions in 2003 for the whole of China vary from a minimum of $\sim 20 \mathrm{Mg}$ to a maximum of $\sim 280 \mathrm{Mg}$ (see Fig. 3a), an order of magnitude different. The difference is even larger at the province level. Total $\mathrm{Hg}$ emissions in 2003 for Guizhou range from a minimum of $\sim 0.2 \mathrm{Mg}$ to a maximum of $\sim 30 \mathrm{Mg}$ (see Fig. $4 \mathrm{a}$ ), two orders of magnitude different. The largest source of uncertainty is this factor: Hg content in coal. From Figs. 3 and 4, we can see that the output distribution curves are close to "lognormal" shape; and this shape is especially clear for some specific provinces, such as Guizhou. From our distribution function database for

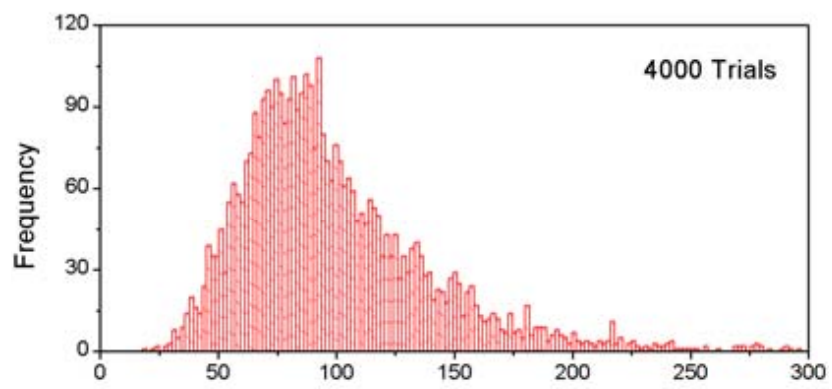

(a) Total $\mathrm{Hg}$ emissions $(\mathrm{Mg}$ )

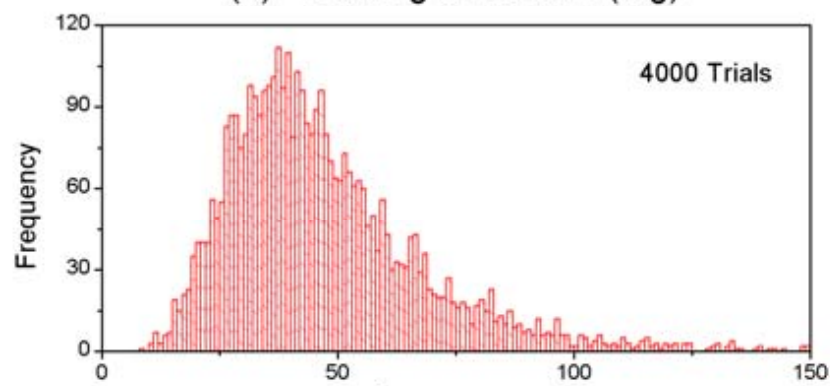

(b) $\mathrm{Hg}^{0}$ emissions $(\mathrm{Mg})$

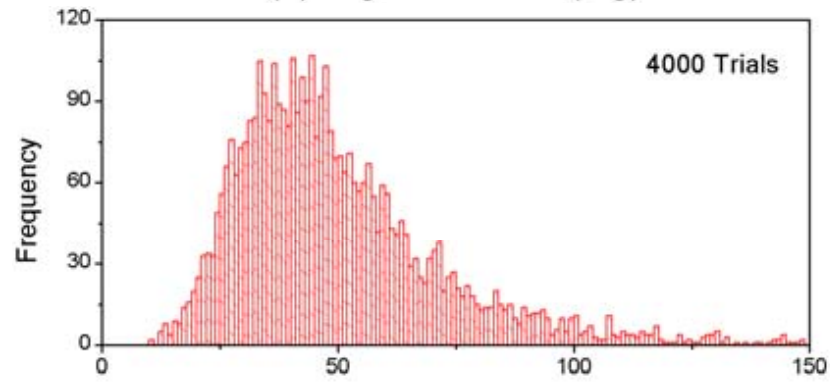

(c) $\mathrm{Hg}^{2+}$ emssions ( $\mathrm{Mg}$ )

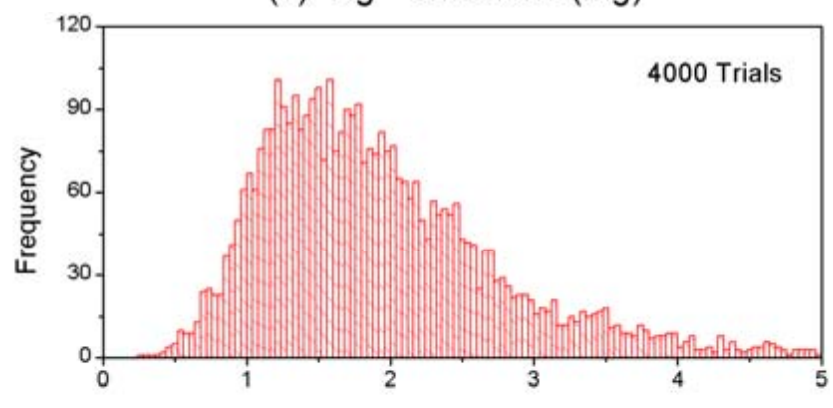

(d) $\mathrm{Hg}^{\mathrm{p}}$ emissions $(\mathrm{Mg})$

Fig. 3. The output distribution function curves for emissions of (a) total $\mathrm{Hg}$, (b) $\mathrm{Hg}^{0}$, (c) $\mathrm{Hg}^{2+}$, and (d) $\mathrm{Hg}^{p}$, from coal-fired power plants in China in 2003.

the key input parameters, only the parameter $\mathrm{Hg}$ content in coal shows a lognormal distribution. The long tails in the output curves for emissions of total $\mathrm{Hg}$ and its three species for Guizhou are no doubt caused by the distribution of the $\mathrm{Hg}$ content of Guizhou's coal, which is highly variable (the difference between the maximum and minimum is as high as 


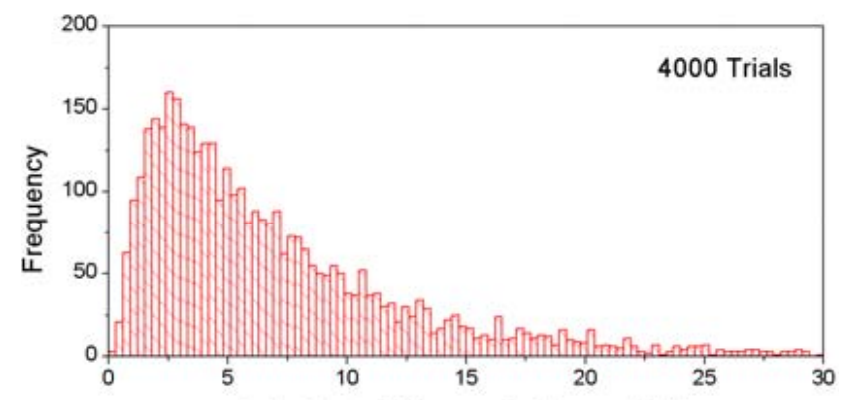

(a) Total $\mathrm{Hg}$ emissions (Mg)

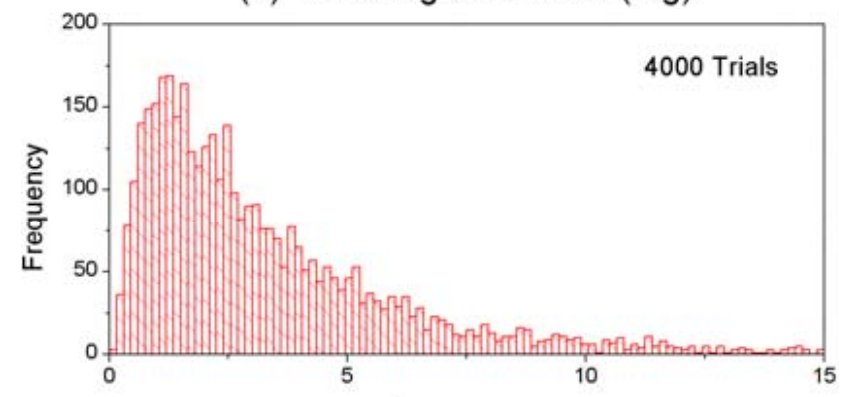

(b) $\mathrm{Hg}^{0}$ emissions $(\mathrm{Mg})$

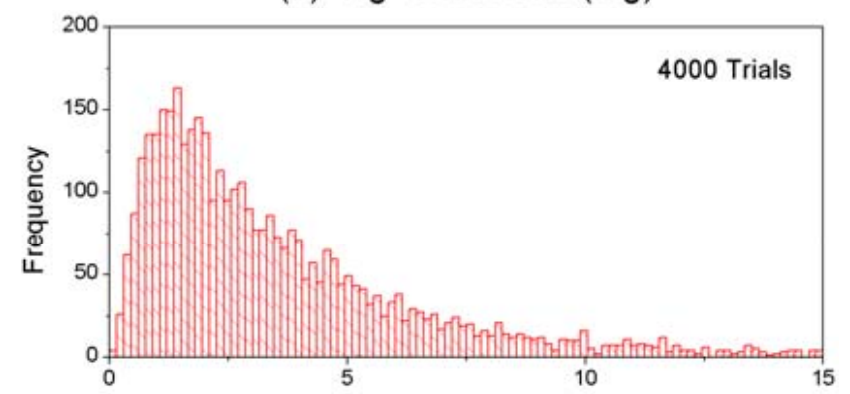

(c) $\mathrm{Hg}^{2+}$ emissions $(\mathrm{Mg})$

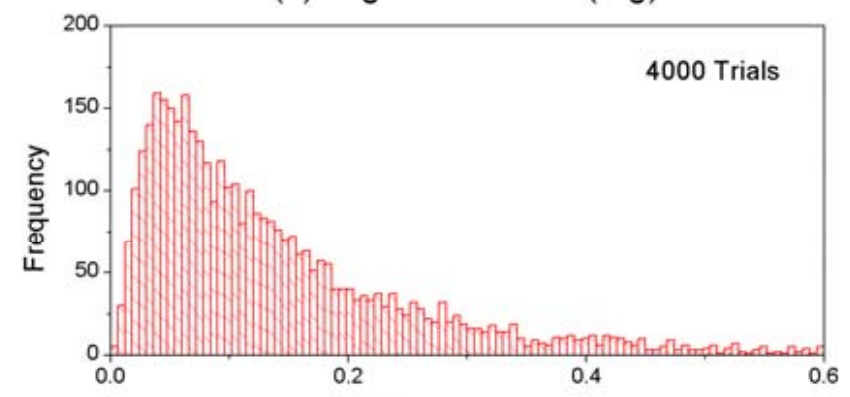

(d) $\mathrm{Hg}^{\mathrm{p}}$ emissions (Mg)

Fig. 4. The output distribution function curves for emissions of (a) total $\mathrm{Hg}$, (b) $\mathrm{Hg}^{0}$, (c) $\mathrm{Hg}^{2+}$, and (d) $\mathrm{Hg}^{p}$, from coal-fired power plants in Guizhou in 2003.

200). Furthermore, we designed several scenarios to evaluate the contributions of various parameters to the uncertainty in Hg emissions (see Table 3). As shown for Scenario 1 in Table 3 , the parameter, $\mathrm{Hg}$ content in coal, plays the dominant role in determining the best estimate of total $\mathrm{Hg}$ emissions in China and Guizhou Province, as well as the uncertainty range.

In previous studies (Streets et al., 2005; Wu et al., 2006), we thought that the activity level contributed a somewhat similar uncertainty as the emission factor. However, from this study, at least for the power-plant sector, this is not the case. First, the differences in coal consumption for most provinces are quite small (within $\pm 5 \%$ ). Second, the clean coal consumption in the power sector in China is small, only $2.2 \%$, although this key parameter, the ratio of cleaned coal output to raw coal input, involved in calculating $\mathrm{Hg}$ emissions from clean coal, shows a moderate uncertainty range $(-16 \% /+15 \%)$. As a result, the activity level in the power sector in China plays only a small role in the uncertainty estimate, as confirmed by the results of Scenarios 4 and 5 in Table 3.

$\mathrm{Hg}$ removal efficiency is also a major factor affecting the uncertainty. This is especially true for $\mathrm{Hg}$ removal efficiency by ESP, as ESP is the dominant control device in China's coal-fired plants. The uncertainty range for this parameter is wide, at $\pm 70 \%$. As shown by Scenario 2 in Table 3, the parameter, $\mathrm{Hg}$ removal efficiency by ESP, ranks as the second most important parameter affecting the uncertainty range of total $\mathrm{Hg}$ emissions in China and Guizhou Province. In the future, $\mathrm{Hg}$ removal efficiency by ESP plus FGD could also play an important role, because the share of FGD to total power capacity will reach over $80 \%$ within the next decade (Wang et al., 2010b). The current uncertainty range for $\mathrm{Hg}$ removal efficiency by ESP plus FGD is not large, at $\pm 9 \%$; however, it should be noted this range is based on a very limited dataset. The uncertainty level could become larger as more test data come available. The two parameters, $\mathrm{Hg}$ removal efficiency by FGD and $\mathrm{Hg}$ removal efficiency by coal washing, contribute a small share of the uncertainty level in the output distribution curve, as these two control technologies are not popular in the power sector in China.

With the output distribution curves, we can summarize the statistical results for each province and for the whole of China in four separate charts: total $\mathrm{Hg}, \mathrm{Hg}^{0}, \mathrm{Hg}^{2+}$ and $\mathrm{Hg}^{p}$, as shown in Fig. 5a-d. The bar represents the P50 value of emissions, and the line superimposed on each bar represents the range between the P10 and P90 values. Thus, for the whole of China in 2003, (a) the best estimate for total $\mathrm{Hg}$ emissions from coal-fired power plants is $90.5 \mathrm{Mg}$, with the uncertainty range from $57.1 \mathrm{Mg}$ (P10) to $154.6 \mathrm{Mg}$ (P90); (b) the best estimate for $\mathrm{Hg}^{0}$ emissions is $43.0 \mathrm{Mg}$, with the uncertainty range from $25.6 \mathrm{Mg}(\mathrm{P} 10)$ to $75.7 \mathrm{Mg}$ (P90); (c) the best estimate for $\mathrm{Hg}^{2+}$ emissions is $45.4 \mathrm{Mg}$, with the uncertainty range from $27.3 \mathrm{Mg}$ (P10) to $80.2 \mathrm{Mg}$ (P90); and (d) the best estimate for $\mathrm{Hg}^{p}$ emissions is $1.8 \mathrm{Mg}$, with the uncertainty range from $1.0 \mathrm{Mg}(\mathrm{P} 10)$ to $3.2 \mathrm{Mg}$ (P90). The previous point estimate for total $\mathrm{Hg}$ emissions from the power sector in China in 2003 was $100.1 \mathrm{Mg}$ (Wu et al., 2006), $10.6 \%$ higher than our new best estimate. The lower P50 value as compared with the previous mean value is primarily 

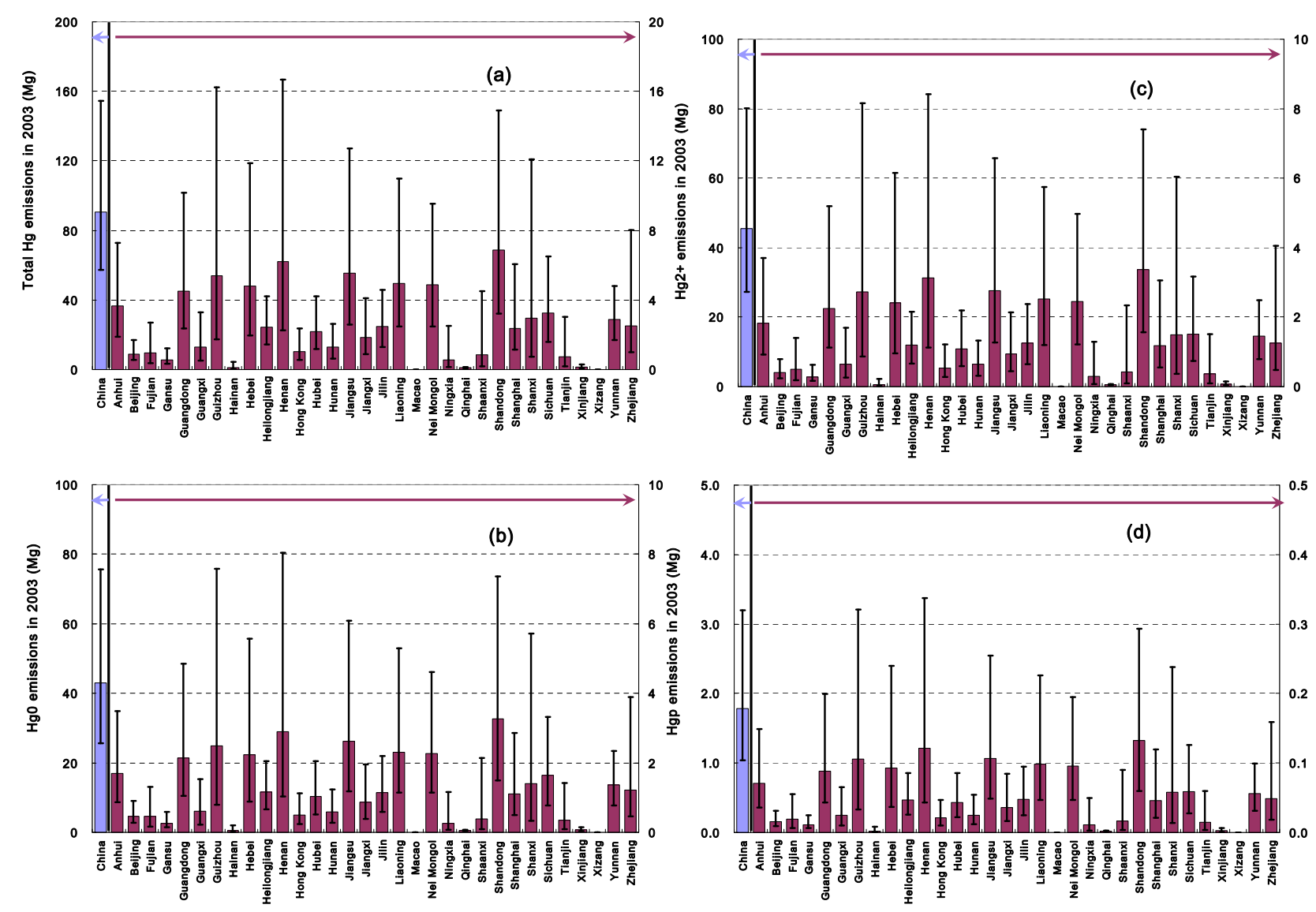

Fig. 5. The best estimate and its uncertainty range of emissions of (a) total $\mathrm{Hg}$, (b) $\mathrm{Hg}^{0},(\mathbf{c}) \mathrm{Hg}^{2+}$, and (d) $\mathrm{Hg}^{p}$, from coal-fired power plants for the whole of China and by each province in 2003. The bar represents the P50 value, i.e., the best estimate of emissions, and the line superimposed on each bar represents the range between the P10 and P90 values.

attributed to the factor, $\mathrm{Hg}$ content in coal. The use of lognormal distribution curves for this parameter shifts the P50 value to a lower number. It should be noted that the uncertainty range is large, for example, $-37 \% /+71 \%$ for the total $\mathrm{Hg}$ emission estimate. The larger uncertainty at the right high-value bound (i.e., $+71 \%$ ) is primarily due to the long tail of the distribution of the $\mathrm{Hg}$ content of coal. $\mathrm{Hg}^{0}$ emissions, $43.0 \mathrm{Mg}$, are much higher than our previous estimate (Wu et al., 2006), which was $20.0 \mathrm{Mg}$, because of incorporation of the new measured speciation data. This may help to close at least a portion of the gap between the $\mathrm{Hg}^{0}$ emission inventory estimate and $\mathrm{Hg}^{0}$ atmospheric observations in previous field studies (Friedli et al., 2004; Jaffe et al., 2005; Pan et al., 2006; Weiss-Penzias et al., 2007). Conversely, $\mathrm{Hg}^{2+}$ emissions in this study, $45.4 \mathrm{Mg}$, are considerably lower than our previous estimate $(78.1 \mathrm{Mg}) . \mathrm{Hg}^{P}$ emissions are quite close, $1.8 \mathrm{Mg}$ vs. $2.0 \mathrm{Mg}$.

The top five provinces in total $\mathrm{Hg}$ emissions from the power sector in 2003 are as follows: Shandong $(6.9 \mathrm{Mg}$, $-53 \% /+116 \%)$, Henan $(6.2 \mathrm{Mg},-64 \% /+169 \%)$, Jiangsu $(5.5 \mathrm{Mg},-53 \% /+130 \%)$, Guizhou $(5.4 \mathrm{Mg},-68 \% /+200 \%)$, and Liaoning $(5.0 \mathrm{Mg},-50 \% /+121 \%)$. These five provinces contribute about one-third of the total national emissions. It should be noted that the uncertainty range (especially at the right high-value bound) at the provincial level is significantly higher than for the national estimate. For example, the P90 value for Guizhou's total $\mathrm{Hg}$ emission estimate is as high as $16.2 \mathrm{Mg}$, two times higher than the best estimate (P50 value). Further, the uncertainty level varies from one province to another. The larger uncertainty range for provinces such as Guizhou and Henan is primarily attributed to high uncertainty in the Hg content of coal there.

\section{Conclusions}

The results of stochastic simulations from this study show that the majority of the uncertainty in $\mathrm{Hg}$ emission estimation results from one key factor, the mercury content of coal. In addition, the mercury removal efficiency of ESP also plays an important role in $\mathrm{Hg}$ uncertainty. As China is accelerating the installation of FGD systems to control $\mathrm{SO}_{2}$ emissions, 
the Hg removal efficiency by ESP plus FGD could also be another major factor in the near future.

The best estimate for total $\mathrm{Hg}$ emissions from coal-fired power plants in China in 2003 is $90.5 \mathrm{Mg}$, with the uncertainty range from $57.1 \mathrm{Mg}(\mathrm{P} 10)$ to $154.6 \mathrm{Mg}$ (P90). The best estimate is about $10 \%$ lower than our previous point estimate for China $(100.1 \mathrm{Mg})$, and the uncertainty range is large $(-37 \% /+71 \%)$. The best estimate for $\mathrm{Hg}^{0}$ emissions, $43.0 \mathrm{Mg}(-40 \% /+76 \%)$, is $115 \%$ higher than our previous point estimate $(20.0 \mathrm{Mg})$. Conversely, the best estimate for $\mathrm{Hg}^{2+}$ emissions in this study, $45.4 \mathrm{Mg}(-40 \% /+77 \%)$, is $43 \%$ lower than our previous estimate $(78.1 \mathrm{Mg}) . \mathrm{Hg}^{P}$ emissions are small and quite similar in both studies.

The top five provinces in total $\mathrm{Hg}$ emissions from power sector in 2003 are Shandong $(6.9 \mathrm{Mg},-53 \% /+116 \%)$, Henan $(6.2 \mathrm{Mg},-64 \% /+169 \%)$, Jiangsu $(5.5 \mathrm{Mg},-53 \% /+130 \%)$, Guizhou $(5.4 \mathrm{Mg},-68 \% /+200 \%)$, and Liaoning $(5.0 \mathrm{Mg}$, $-50 \% /+121 \%)$. The uncertainty range at the provincial level is significantly higher than that for the national estimate. The uncertainty level varies significantly from one province to another. The larger uncertainty range for provinces such as Guizhou and Henan is primarily attributed to high variability in the $\mathrm{Hg}$ content of coal in those provinces.

Uncertainties exist in all of the variables involved in the calculation of $\mathrm{Hg}$ emissions, and some of them are quite large. Thus a stochastic simulation, such as we have adopted in this work, is better than a deterministic approach and comes closer to a true reflection of reality. Currently, the database of $\mathrm{Hg}$ content in bituminous coal for some major provinces (such as Shanxi) has been well established due to extensive measurements. Similarly, the $\mathrm{Hg}$ profiles of ESP for bituminous coal in pulverized coal boilers have recently been investigated in detail. However, many other parameters are poorly known due to lack of measurements. More effort is needed to gather information on important parameters, if the emission inventory is to be improved. For example, we are still lacking field test profiles to build distribution curves for control technologies such as FGD plus ESP, which is becoming the leading control technology in China's power plants. Also, the new technology for $\mathrm{NO}_{\mathrm{x}}$ emission reduction, selective catalytic reduction (SCR), is beginning to penetrate the power sector in China, and its $\mathrm{Hg}$ removal mechanisms need to be explored. As soon as these data become available, an update of our emission inventory will be performed.

Acknowledgements. This work was sponsored by (1) State Key Joint Laboratory of Environment Simulation and Pollution Control (08Z03ESPCT), (2) the National Natural Science Foundation of China (20937002), and (3) the National Energy Technology Laboratory, which is owned and operated by the US Department of Energy (DOE). Argonne National Laboratory is operated by UChicago Argonne, LLC, under Contract No. DE-AC0206CH11357 with the US Department of Energy.

Edited by: R. Ebinghaus

\section{References}

China Power Industry: 2004 China Power Yearbook. China Power Press, Beijing, China, 2004.

Banic, C. M., Beauchamp, S. T., Tordon, R. J., Schroeder, W. H., Steffen, A., Anlauf, K. A., and Wong, H. K. T.: Vertical distribution of gaseous elemental mercury in Canada. J. Geophys. Res., 108(D9), 4264, doi:10.1029/2002JD002116, 2003.

Brinkman, N., Wang, M., Weber, T., and Darlington, T.: Well-to-wheels analysis of advanced fuel/vehicle systemsa North American study of energy use, greenhouse gas emissions, and criteria pollutant emissions. Online available at: http://www.transportation.anl.gov/software/GREET/ publications.html, 2005.

Chen, L.; Duan, Y.; Zhuo, Y.; Yang, L.; Zhang, L.; Yang, X.; Yao, Q.; Jiang, Y.; Xu, X.: Mercury transformation across particulate control devices in six power plants of China: The co-effect of chlorine and ash composition. Fuel, 86(4), 603-610, 2007.

Dastoor, A. P. and Larocque, Y.: Global circulation of atmospheric mercury: a modeling study. Atmos. Environ., 38, 147-161, 2004.

Jaffe, D., Prestbo, E., Swartzendruber, P., Weiss-Penzias, P., Kato, S., Takami, A., Hatakeyama, S., and Kajii, Y.: Export of atmospheric mercury from Asia. Atmos. Environ., 39, 3029-3038, 2005.

Fang, F., Wang, Q., Liu, R., Ma, Z., and Hao, Q.: Atmospheric particulate mercury in Changchun City, China, Atmos. Environ. 35, 4265-4272, 2001

Fu, X., Feng, X., Wang, S., Rothenberg, S., Shang, L., Li, Z., and Qiu, G.: Temporal and spatial distributions of total gaseous mercury concentrations in ambient air in a mountainous area in southwestern China: Implications for industial and domestic mercury emissions in remote areas in China, Sci. Total Environ., 407, 2306-2314, 2009.

Fu, X. W., Feng, X., Dong, Z. Q., Yin, R. S., Wang, J. X., Yang, Z. R., and Zhang, H.: Atmospheric gaseous elemental mercury (GEM) concentrations and mercury depositions at a high-altitude mountain peak in south China, Atmos. Chem. Phys., 10, 24252437, 2010, http://www.atmos-chem-phys.net/10/2425/2010/.

Feng, X., Sommer, J., Lindqvist, O., and Hong, Y.: Occurrence, emissions and deposition of mercury during coal combustion in the province Guizhou, China, Water Air Soil Pollut., 139, 311324, 2002.

Feng, X., Tang, S., Shang, L., Yan, H., Sommar, J., and Lindqvist, O.: Total gaseous mercury in the atmosphere of Guiyang, PR China, Sci. Total Environ., 304, 61-72, 2003.

Feng, X., Shang, L., Wang, S., Tang, S., and Zheng, W.: Temporal variation of total gaseous mercury in the air of Guiyang, China, J. Geophys. Res., 109, D03303, doi:10.1029/2003JD004159, 2004a.

Feng, X., Yan, H., Wang, S., Qiu, G., Tang, S., Shang, L., Dai, Q., and Hou, Y.: Seasonal variation of gaseous mercury exchange rate between air and water surface over Baihua reservoir, Guizhou, China. Atmos. Environ., 38, 4721-4732, 2004b.

Feng, X.: Mercury pollution in China - an overview. In: Dynamics of Mercury Pollution on Regional and Global Scales: Atmospheric Processes, Human Exposure Around the World, edited by: Pirrone, N. and Mahaffey, K. Springer Publishers, Norwell, MA, USA, 657-678, 2005.

Friedli, H. R., Radke, L. F., Prescott, R., Li, P., Woo, J.-H., and Carmichael, G. R.: Mercury in the atmosphere around Japan, Ko- 
rea, and China as observed during the 2001 ACE-Asia field campaign: measurements, distributions, sources, and implications. J. Geophys. Res., 109, D19S25, doi:10.1029/2003JD004244, 2004.

Huang, W. and Yang, Y.: Mercury in coal in China. Coal Geology of China, 14(S), 37-40, 2002.

Lindberg, S., Bullock, R., Ebinghaus, R., Engstrom, D., Feng, X., Fitzgerald, W., Pirrone, N., Prestbo, E., and Seigneur, C.: A synthesis of progress and uncertainties in attributing the sources of mercury in deposition. Ambio, 36(1), 19-32, 2007.

Liu, S., Nadim, F., Perkins, C., Carley, R. J., Hoag, G. E., Lin, Y., and Chen, L.: Atmospheric mercury monitoring survey in Beijing, China, Chemosphere, 48, 97-107, 2002.

National Bureau of Statistics of China, P.R. China: China Energy Statistical Yearbook (2003). China Statistics Press, Beijing, China, 2005.

Pacyna, J. M. and Pacyna, E. G.: Global emissions of mercury to the atmosphere. Emissions from anthropogenic sources; Arctic Monitoring and Assessment Programme (AMAP), Oslo, Norway, 1996.

Pacyna, E. G. and Pacyna, J. M.: Global emission of mercury from anthropogenic sources in 1995. Water Air Soil Pollut., 137, 149$165,2002$.

Pacyna, E. G., Pacyna, J. M., Steenhuisen, F., and Wilson, S.: Global anthropogenic mercury emission inventory for 2000, Atmos. Environ., 40, 4048-4063, 2006.

Pan, L., Woo, J.-H., Carmichael, G. R., Tang, Y., Friedli, H. R., and Radke, L. F.: Regional distribution and emissions of mercury in east Asia: A modeling analysis of Asian Pacific Regional Aerosol Characterization Experiment (ACE-Asia) observations. J. Geophys. Res., 111, D07109, doi:10.1029/2005JD006381, 2006.

Seigneur, C., Karamchandani, P., Lohman, K., Vijayaraghavan, K., and Shia, R.-L.: Multiscale modeling of the atmospheric fate and transport of mercury, J. Geophys. Res., 106(D21), 27795-27809, 2001.

Seigneur, C., Vijayaraghavan, K., Lohman, K., Karamchandani, P., and Scott, C.: Global source attribution for mercury deposition in the United States. Environ. Sci. Technol., 38(2), 555-569, 2004.

Steding, D. J. and Flegal, A. R.: Mercury concentrations in coastal California precipitation: evidence of local and trans-Pacific fluxes of mercury to North America. J. Geophys. Res., 107(D24), 4764, doi:10.1029/2002JD002081, 2002.

Selin, N. E., Jacob, D. J., Park, R. J., Yantosca, R. M., Strode, S., Jaegle, L., and Jaffe, D.: Chemical cycling and deposition of atmospheric mercury: global constraints from observations. J. Geophys. Res., 112, D02308, doi:10.1029/2006JD007450, 2007.

Srivastava, R. K., Hutson, N., Martin, B., and Princiotta, F.: Control of mercury emissions from coal-fired electric utility boilers. Environ. Sci. Technol., 40(5), 1385-1393, 2006.

Streets, D. G., Bond, T. C., Carmichael, G. R., Fernandes, S. D., Fu, Q., He, D., Klimont, Z., Nelson, S. M., Tsai, N. Y., Wang, M. Q., Woo, J.-H., and Yarber, K. F.: An inventory of gaseous and primary aerosol emissions in Asia in the year 2000. J. Geophys. Res., 108(D21), 8809, doi:10.1029/2002JD003093, 2003a.

Streets, D. G., Yarber, K. F., Woo, J.-H., and Carmichael, G. R.: Biomass burning in Asia: Annual and seasonal estimates and atmospheric emissions, Global Biogeochem. Cy., 17(4), 1099, doi:10.1029/2003GB002040, 2003b.
Streets, D. G., Hao, J. M., Wu, Y., Jiang, J. K., Chan, M., Tian, H. Z., and Feng, X. B.: Anthropogenic mercury emissions in China. Atmos. Environ., 39, 7789-7806, 2005.

Streets, D. G., Hao, J., Wang, S., and Wu, Y.: Mercury emissions from coal combustion in China, in Mercury Fate and Transport in the Global Atmosphere: Measurements, Models and Policy Implications, edited by: Pirrone, N. and Mason, R., United Nations Environment Programme, 2008.

Subramanyan, K., Wu, Y., Diwekar, U. M., and Wang, M. Q.: New stochastic simulation capability applied to the GREET model. Int. J. LCA., 13(3), 278-285, 2008.

Travnikov, O. and Ryaboshapko, A.: Modelling of Mercury Hemispheric Transport and Depositions. MSC-E Technical Report 6/2002. Meteorological Synthesizing Centre-East, Moscow, Russia, 67 pp., 2002.

US Geological Survey (USGS): Mercury content in coal mines in China (unpublished data), 2004.

US Environmental Protection Agency (US EPA): Mercury Study Report to Congress, Volume II: An Inventory of Anthropogenic Mercury Emissions in the United States, EPA-452/R-97-004, 1997.

US Environmental Protection Agency (US EPA): Research and Development: Characterization and Management of Residues from Coal-fired Power Plants, EPA-600/R-02-083, 2002.

Weiss-Penzias, P., Jaffe, D., Swartzendruber, P., Hafner, W., Chand, D., and Prestbo, E.: Quantifying Asian and biomass burning sources of mercury using the $\mathrm{Hg} / \mathrm{CO}$ ratio in pollution plumes observed at the Mount Bachelor observatory. Atmos. Environ., 41, 4366-4379, 2007.

Wan, Q., Feng, X., Lu, J., Zheng, W., Song, X., Han, S., and Xu, H.: Atmospheric mercury in Changbai Mountain area, northeastern China I. The seasonal distribution pattern of total gaseous mercury and its potential sources. Environ. Res., 109, 201-206, 2009.

Wang, Q., Shen, W., and Ma, Z.: Estimation of mercury emission from coal combustion in China, Environ. Sci. Technol., 34, 2711-2713, 2000.

Wang, S. X., Zhang, L., Li, G. H., Wu, Y., Hao, J. M., Pirrone, N., Sprovieri, F., and Ancora, M. P.: Mercury emission and speciation of coal-fired power plants in China, Atmos. Chem. Phys., 10, 1183-1192, 2010a, http://www.atmos-chem-phys.net/10/1183/2010/.

Wang, S. X., Zhang, L., Wu, Y., Ancora, M. P., Zhao, Y., and Hao, J. M.: Synergistic mercury removal by conventional pollutant control strategies for coal-fired power plants in China, J. Air Waste Manage. Assoc., 60, doi:10.3155/1047-3289.60.5.1, 2010b.

Wu, Y., Wang, S. X., Streets, D. G., Hao, J. M., Chan, M., and Jiang, J. K.: Trends in anthropogenic mercury emissions in China from 1995 to 2003. Environ. Sci. Technol., 40, 5312-5318, 2006.

Zhang, J., Ren, D., Xu, D., and Zhao, F.: Mercury in coal and its effect on environment, Adv. Environ. Sci., 7(3), 100-104, 1999.

Zhang, L., Zhuo, Y., Chen, L., Xu, X., and Chen, C.: Mercury emissions from six coal-fired power plants in China, Fuel Process. Technol., 89(11), 1033-1040, 2008.

Zhou, J., Zhang, L., Luo, Z., and Hu, C.: Study on mercury emission and its control for boiler of $300 \mathrm{MW}$ unit. Thermal Power Generation, 37(4), 22-27, 2008.

Zhu, Z., Xu, L., and Tan, Y.: Research on characteristics of mercury distribution in combustion products for a 300MW pulverized coal fired boiler, Power Eng., 22, 1594-1597, 2002. 